\title{
ABSTINENSI DAN PENDIDIKAN SEKS REMAJA: SURVEI CEPAT DI JAKARTA DAN SEKITARNYA
}

\author{
Nurfadhilah $^{1}$, Ariasih $^{2}$ \\ ${ }^{1,2}$ Fakultas Kesehatan Masyarakat Universitas Muhammadiyah Jakarta Gedung FKK Jl. KH Ahmad \\ Dahlan Cireundeu, Ciputat, Tangerang Selatan, Indonesia, 14519 nurfadhilah.nf@umj.ac.id
}

\begin{abstract}
Indonesian teenagers are getting smarter and having higher achievements, yet experiencing disadvantage situation. Surveys revealed that their health knowledge/literacy and behavior are not getting better even though information access raising. Education (intra and extra curricula) is one of strongest strategy to intervene the fundamental problems. A rapid survey was conducted to assess abstinence and the need of sex education for adolescents in Jakarta and surrounding areas. Data were collected from 163 respondents interviewed at their schools or community. As much as 65\% said they never had any kind of sexual activity (primary abstainers) and $81.6 \%$ said they need sex education with an offline (face to face) methode 47.8\%. Adolescent's sexual education in Indonesia is indeed an urgent need. An integrative and comprehensive sex education along with adolescent (and pre-adolescent) developmental stages, cultural, and religious values regarding the affect on future health should be undertake.
\end{abstract}

Keywords: abstinence, adolescent, sex, education

\begin{abstract}
Abstrak
Remaja Indonesia semakin cerdas dan memiliki pencapaian yang semakin tinggi, namun pada saat yang sama mengalami situasi yang tidak menguntungkan. Beberapa hasil survey menunjukkan bahwa pengetahuan/literasi kesehatan mereka tidak semakin baik padahal akses terhadap informasi sangat tinggi. Pendidikan (intra dan ekstra-kurikuler) merupakan salah satu strategi terkuat untuk mengintervensi masalah mendasar. Survei cepat dilakukan untuk menilai perilaku abstinensi (puasa seks) dan kebutuhan pendidikan seks remaja di Jakarta dan kota-kota sekitarnya. Data dikumpulkan dari 163 responden yang diwawancara di sekolah atau komunitasnya. Sebanyak 65\% remaja mengaku melakukan abstinensi primer (tidak pernah melakukan aktivitas seksual) dan 81,6\% menyatakan kebutuhannya akan pendidikan seks, dengan cara tatap muka 47,8\%. pendidikan seks di Indonesia sejatinya merupakan kebutuhan mendesak. Pendidikan seks integratif dan komprehensif sesuai dengan tahapan perkembangan remaja (dan pra remaja), nilai budaya dan agama yang dianut serta tetap memperhatikan dampaknya terhadap kesehatan generasi mendatang harus segera dilakukan.
\end{abstract}

Kata kunci: abstinensi, remaja, seks, pendidikan

\begin{tabular}{|l|l|l|l|}
\hline Volume XX & Nomor 1 & Maret 2019 & e-ISSN : 2580-9199 \\
\hline
\end{tabular}




\section{PENDAHULUAN}

Pasca Tujuan Pembangunan Milenium, para pemimpin dunia menyepakati target rumusan berikutnya yaitu Tujuan Pembangunan Berkelanjutan. Beberapa di antara 17 tujuan tersebut berkaitan langsung dengan kependudukan dan pendidikan, di antaranya tujuan 3 (kehidupan sehat dan sejahtera), tujuan 4 (pendidikan berkualitas). Indonesia saat ini mengalami bonus demografi (BPS, 2017) yang puncaknya diperkirakan pada 2030. Situasi ini perlu diantisipasi agar tidak terjadi sebaliknya, beban atau bahkan bencana demografi. Kekhawatiran ancaman/potensi kegagalan SDGs (sebagaimana MDGs) muncul saat ini, ketika program edukasi hanya-abstinensi (abstinence-only education) direvitalisasi (padahal dianggap terbukti gagal mencegah remaja menjadi aktif seksual) dan beberapa program lain dikurangi/dihentikan. Sejatinya pemenuhan hak reproduksi dan seksual dibutuhkan seluruh lapisan masyarakat sepanjang tahapan usia. Dibutuhkan kesepakatan dan pandangan luas serta jauh ke depan dalam menentukan batasan dan kebutuhan program komprehensif (Biccard, 2018). Penentuan batasan dimaksud akan mengarahkan materi dan pola pendidikan seks bagi remaja yang sesuai dengan nilai yang dianut masyarakat Indonesia serta sesuai dengan pendidikan karakter yang merupakan acuan kurikulum terkini.

Remaja Indonesia dewasa ini semakin cerdas dan berprestasi, namun pada saat yang sama juga mengalami banyak situasi yang tidak menguntungkan.

Data Survei Kesehatan Reproduksi Remaja (15-19 dan 20-24 tahun) Indonesia 2017 menunjukkan betapa pengetahuan remaja tentang tanda pubertas masih sangat perlu ditingkatkan. Padahal, pubertas jelas-jelas terjadi pada masa remaja, itu artinya mereka bahkan tidak (mau) memahami/menyadari proses internal yang sedang terjadi. Kurang dari $10 \%$ remaja baik laki-laki maupun perempuan tahu bahwa salah satu tanda pubertas yaitu peningkatan gairah seks. Angka tertinggi dicapai pada pengetahuan perempuan tentang indikator perubahan fisik mulai haid $(87,8 \%$ pada perempuan usia 15-19 tahun dan 90,5\% pada perempuan usia 20-24 tahun). Sedangkan pada laki-laki, indikator paling banyak diketahui yaitu pembesaran payudara perempuan $(58,1$ dan $62,5 \%)$. Indikator perubahan fisik laki-laki umumnya 
angkanya lebih rendah (Center for Population Research and Development \& Family Planning Board, 2018). Hal ini sangat perlu diwaspadai karena dikhawatirkan mereka kurang bahkan tidak sempat mengantisipasi pubertas dan permasalahan yang terjadi pasca peristiwa ini.

Rendahnya pengetahuan remaja berbanding terbalik dengan akses terhadap media, khususnya media elektronik. Hampir 90\% remaja mengakses internet dalam 1 tahun dan 1 bulan terakhir, pada kisaran 86-89\% (Center for Population Research and Development \& Family Planning Board, 2018). Revolusi media yang sangat terbuka dan sangat mudah untuk diakses oleh semua kalangan terutama remaja berdampak pada informasi yang didapat tidak hanya bersifat edukatif dan informatif saja melainkan dapat menyesatkan dan menjerumuskan remaja kepada perilaku menyimpang dan mengacaukan fungsi normal kesehatan, khususnya kesehatan reproduksinya.

$$
\text { Informasi tersebut dapat }
$$

berkontribusi terhadap fungsi kognitif dan mengarahkan emosi serta perilaku yang berisiko terhadap kesehatan dan pengembangan dirinya di masa datang. Situasi ini sangat tidak menguntungkan bagi bangsa Indonesia yang saat ini sedang mengalami bonus demografi. Hal ini sangat perlu diwaspadai karena dikhawatirkan kaum muda kurang bahkan tidak sempat mengantisipasi pubertas dan permasalahan yang terjadi pasca peristiwa ini. Penelitian ini bertujuan menggambarkan perilaku abstinensi remaja di Jakarta dan sekitarnya serta kebutuhan mereka akan pendidikan terkait abstinensi.

\section{METODOLOGI}

Penelitian ini menggunakan pendekatan kuantitatif dengan desain studi survei cepat. Data diambil dari 20 klaster institusi formal (sekolah dan perguruan tinggi) dan informal (keagamaan, sosial, klub hobi-misalnya komunitas vape). Setiap klaster terdiri dari sekurangkurangnya 7 responden yang diambil secara aksidental, populasi remaja dan dewasa belum pernah menikah. Data diambil pada November-Desember 2018 oleh enumerator dengan kriteria mahasiswa Program Studi Kesehatan Masyarakat yang sudah diberikan pelatihan wawancara pengumpulan data. Data yang sudah dikumpulkan dalam bentuk rekaman suara, transkrip hasil wawancara dan fomulir/kuesioner yang diisi oleh pewawancara.

Informasi tentang perilaku abstinensi didapat dari instrumen terdiri dari 
pertanyaan tentang 1) pernah atau tidak melakukan aktivitas seksual, 2) bersama siapa, 3) bagaimana (suka rela-dengan ancaman) 4) kapan aktivitas seksual terakhir dilakukan. Perilaku abstinensi didefinisikan sebagai perilaku seseorang yang menghindari segala jenis aktivitas yang bertujuan untuk merangsang hasrat seksual mulai dari sentuhan pada bagian tubuh hingga penetrasi per vaginal, anal, maupun oral. Perilaku abstinensi juga termasuk jika aktivitas seksual yang dilakukan tanpa pasangan (menggunakan atau tanpa objek lain) dihindari/tidak pernah dilakukan.

Pertanyaan tentang kebutuhan pendidikan kesehatan reproduksi remaja terdiri dari 1) perlu atau tidak pendidikan seks dan 2) cara (online atau offline/tatap muka) dan 3) lainnya.

\section{HASIL DAN PEMBAHASAN}

\section{Keterbatasan Penelitian}

Desain penelitian survai cepat seharusnya dilakukan di 30 klaster dengan jumlah sampel minimal tiap klaster 7 , namun dalam penelitian ini hanya terkumpul data dari 20 klaster. Pengumpulan data dilakukan dengan tahapan wawancara karena topik penelitian cukup sensitif dan responden sangat bervariasi (kelompok umur dan jenis institusi/komunitas). Beberapa informasi karakteristik responden tidak ditanyakan untuk meningkatkan keterbukaan responden terhadap fokus penelitian.

\section{Perilaku Abstinensi}

Total responden yang berhasil dikumpulkan datanya sebanyak 163 orang dengan karakteristik remaja atau dewasa tidak pernah menikah. Seluruh responden berada pada rentang usia 12-29 tahun, $74,2 \%$ berjenis kelamin perempuan. Sebanyak $65 \%$ responden mengaku tidak pernah melakukan aktivitas seksual hingga saat data diambil atau abstainer primer (tabel 1.). Beberapa penelitian sebelumnya memang menunjukkan bahwa usia dan gender menjadi variabel penting dalam perilaku abstinensi remaja (Kabiru \& Ezeh, 2007; Smith, Panisch, Malespin, \& Graça Pereira, 2017).

Tabel 1. Distribusi Frekuensi Responden Berdasarkan Karakteristik (Jenis Kelamin) dan Aktivitas Seksual $(\mathbf{n}=163)$

\begin{tabular}{lrc}
\hline Variabel & Frek & $\begin{array}{c}\text { Proporsi } \\
(\mathbf{\%})\end{array}$ \\
\hline Jenis kelamin & & \\
$\quad$ Perempuan & 121 & 74.2 \\
Laki-laki & 42 & 25.8 \\
& & \\
Aktivitas seksual & & \\
$\quad$ Tidak pernah & 106 & 65.0 \\
$\quad$ Pernah & 57 & 35.0 \\
\hline
\end{tabular}


Proporsi remaja yang abstiner dalam penelitian ini berada pada kisaran yang relatif sama dengan beberapa penelitian sebelumnya. Perilaku abstinensi primer (tidak pernah berhubungan seks) remaja laki-laki 15-19 tahun di 4 negara Afrika Sub-Sahara berkisar antara $42 \%$ (Malawi) dan 85\% (Ghana), sedangkan pada perempuan antara 67\% (Uganda) dan 77\% (Ghana) (Kabiru \& Ezeh, 2007). Kecenderungan perilaku abstinensi (baik primer maupun sekunder, batasan 3 bulan) tidak banyak mengalami perubahan dan cukup bervariasi pada 30 negara di Afrika. Tren abstinen primer berkisar antara $62.3 \%$ pada 2001-2005 hingga 54.8\% selama 2011-2015 dan tidak ada perubahan secara signifikan (Ali, Mohamed M. and Cleland, 2018). Sedangkan di Indonesia, data SKRRI 2017 menunjukkan 14\% laki-laki belum menikah berusia 20-24 tahun mengaku pernah melakukan hubungan seks. Seks pranikah di Indonesia masih merupakan perilaku yang dinilai melanggar norma dan nilai yang dianut masyarakat.

Angka kejadian premarital seks di Indonesia tidak setinggi negara-negara Afrika, namun tetap perlu diantisipasi kenaikannya. Remaja Indonesia belum menikah usia 15-24 tahun sebanyak 1,5\% perempuan dan 7,6\% laki-laki pernah melakukan hubungan seks (Center for
Population Research and Development \& Family Planning Board, 2018). Survei sebelumnya (SKRRI 2012) menunjukkan angka $7,1 \%$ remaja telah melakukan hubungan seksual (Pinandari, Wilopo, \& Ismail, 2015). Fenomena gunung es sering digunakan untuk menggambarkan situasi/masalah yang sesungguhnya jauh lebih besar dari pada angka pada hasil survei. Hal ini menunjukkan perlu dilakukan upaya spesifik dan sensitif untuk mencegah situasi dimana remaja yang seharusnya menjadi bagian dari bonus demografi justru menjadi beban, bahkan bencana demografi. Masa persiapan menghadapinya harus dimulai sekarang.

Tabel 2. Distribusi Frekuensi

Responden Berdasarkan Aktivitas

Seksual Pertama dan Terakhir $(n=57)$

\begin{tabular}{lcc}
\hline \multicolumn{1}{c}{ Variabel } & Frek & $\begin{array}{c}\text { Proporsi } \\
(\mathbf{\%})\end{array}$ \\
\hline $\begin{array}{l}\text { Pasangan/objek aktivitas } \\
\text { seks pertama }\end{array}$ & & \\
$\quad \begin{array}{l}\text { Orang dikenal } \\
\text { Orang tidak dikenal }\end{array}$ & 45 & 78,9 \\
$\quad$ Sendiri tanpa alat & 11 & 1,8 \\
& & \\
Inisiasi aktivitas seks & & \\
pertama & 41 & 70,9 \\
$\quad$ Diinginkan & 14 & 25,5 \\
$\quad$ Dirayu & 2 & 3,6 \\
$\quad$ Diancam & & \\
$\quad \begin{array}{l}\text { Waktu aktivitas seksual } \\
\text { terakhir } \\
\quad \text { 3 bulan lalu }\end{array}$ & 37 & 63,6 \\
$\quad$ > 3 bulan lalu & 20 & 36,4 \\
\hline
\end{tabular}

\section{Volume XX}

\section{Nomor 1}

Maret 2019

e-ISSN : 2580-9199 
Tabel 2 memperlihatkan mereka yang pernah melakukan aktivitas seksual $(n=57)$ melakukannya untuk pertama kali pada usia $\leq 15$ tahun $(61,8 \%)$ dengan usia termuda 6 tahun, 78,2\% bersama orang yang dikenal dan 70,9 \% diinginkan (tanpa rayuan atau ancaman). Aktivitas seksual terakhir dilakukan $\leq 3$ bulan lalu $(63,6 \%)$. Peneliti memasukkan individu yang melakukan aktivitas seksual lebih dari 3 bulan lalu sebagai abstainer sekunder (Kabiru \& Ezeh, 2007; Rasberry \& Goodson, 2009).

Penelitian menyebutkan responden masih ada yang bingung dengan istilah "abstinensi," tetapi konsep abstinensi atau memilih untuk tidak melakukan seks jelas dan relevan. Seksual abstinen dianggap sebagai kontinum perkembangan normal. Semua remaja abstinen dalam rentang waktu tertentu, kemudian menjadi aktif seksual ketika merasa siap. Kesiapan dipengaruhi oleh (1) faktor-faktor individual, seperti umur, kejadian dalam hidup, kematangan fisik dan sosial, (2) faktor-faktor relasi seperti bersama orang yang "benar/tepat", atau memiliki komitment dalam relasi, (3) keyakinan moral dan religius, dan (4) keseimbangan risiko dan manfaat kesehatan, sosial, dan keluarga. Seks dianggap memiliki kekuatan, dan transisi menuju seks pertama dianggap ritual peralihan menjadi dewasa. Ada perbedaan umur, gender, dan pengalaman seksual remaja dalam menentukan kesiapan (Ott, Pfeiffer, \& Fortenberry, 2006). Perilaku abstinensinon abstinensi dipersepsi sebagai kontinum perkembangan normal remaja. Jadi remaja, khususnya di negara maju (barat) pada umumnya menganggap pilihan melakukan dan tidak melakukan hubungan/aktivitas seks bisa bergeser tergantung situasi yang dihadapi/dipersepsi. Peran pendidikan seks dalam hal ini yaitu menguatkan/mempertahankan perilaku abstinensi hingga saat mereka siap melaksanakan fungsi reproduksi yang bertanggung jawab (menikah).

Persepsi kesiapan remaja menjadi salah satu tema khusus yang perlu diberi perhatian dalam pendidikan remaja. Temuan-temuan tentang aktivitas seksual remaja dapat dijadikan dasar untuk merancang program pendidikan seks.

\section{Perlukah Pendidikan Seks bagi Remaja} Indonesia?

Hasil penelitian menunjukkan tingginya kebutuhan akan pendidikan seks remaja $(82,1 \%)$. Metode edukasi yang diinginkan responden memiliki kecenderungan agar 
metode tatap muka dilakukan $(64,5 \%)$ dibanding edukasi secara daring (tabel 3).

\begin{tabular}{|c|c|c|}
\hline \multicolumn{3}{|c|}{$\begin{array}{c}\text { Tabel 3. Distribusi Frekuensi } \\
\text { Responden Berdasarkan Kebutuhan } \\
\text { Pendidikan Seks dan Metode } \\
\text { Pendidikan }(\mathbf{n}=163)\end{array}$} \\
\hline Variabel & Frek & $\begin{array}{c}\text { Proporsi } \\
(\%)\end{array}$ \\
\hline \multicolumn{3}{|l|}{ Kebutuhan } \\
\hline $\begin{array}{l}\text { Pendidikan } \\
\text { Perlu }\end{array}$ & 134 & 81.6 \\
\hline Tidak Perlu & 29 & 18.4 \\
\hline \multicolumn{3}{|c|}{ Metode Pendidikan } \\
\hline Online & 43 & 26.4 \\
\hline Offline & 78 & 47.8 \\
\hline Lain-lain & 42 & 25.8 \\
\hline
\end{tabular}

Melihat perkembangan norma dan politik pendidikan seksualitas di negara lain, sebagai contoh di Nigeria terdiri dari 3 fase. Pertama Agenda-setting 19891996; kedua formulasi kebijakan dan adopsi 1997-2002; ketiga Implementasi dan evaluasi 2003-hingga sekarang. Perubahan kurikulum terjadi pada fase 2 dari abstinence-only menjadi Pendidikan Kehidupan Keluarga dan HIV 'Family Life and HIV Education- FLHE' (2002). Penggunaan kata kontrasepsi, masturbasi, aborsti, sexual diversity seperti halnya seksualitas dihilangkan. Konten yang sensitif sosio-kultural dibuat. Pelajar tidak diuji tentang konten. (Shiffman, Kunnuji, Shawar, \& Robinson, 2018). Kearifan lokal menjadi unsur yang sangat perlu diperhitungkan dalam merancang pendidikan seksualitas anak bangsa.
Pertimbangannya termasuk topik spesifik beserta penggunaan istilah yang dapat diterima masyarakat untuk memastikan pesan diterima dan diinternalisasi menjadi perilaku, dalam hal ini ujian tentang konten yang diajarkan tidak menjadi tolok ukur keberhasilan program.

Contoh lain yaitu intervensi pendidikan kesehatan reproduksi dan seksualitas di Amerika Serikat (AS). Data nasional AStahun 2005 bersama kebijakan tentang pendidikan seks menunjukkan bahwa peningkatan penekanan pendidikan abstinensi memiliki korelasi positif dengan kehamilan dan melahirkan pada remaja. Kecenderungan ini tetap signifikan saat diperhitungkan juga status sosial ekonomi, pencapaian pendidikan remaja, komposisi etnik pada populasi remaja, dan ketersediaan/kebebasan fasilitas medik untuk layanan keluarga berencana di setiap negara bagian. Berbagai data menunjukkan dengan jelas bahwa pendidikan hanya-abstinensi (abstinence-only education) sebagai kebijakan negara tidak efektif dalam mencegah kehamilan remaja dan bahkan bisa berkontribusi bagi tingginya angka kehamilan remaja di AS. Terkait dengan Inisiatif Pencegahan Kehamilan Remaja dan Model Proses Adopsi Pencegahan berbasis bukti (the new evidence-based Teen Pregnancy Prevention Initiative and 
the Precaution Adoption Process Model) yang diadvokasi oleh the National Institutes of Health, disarankan integrasi pendidikan seks dan Infeksi Menular Seksual (IMS) dalam kurikulum biologi sekolah menengah pertama dan atas serta kurikulum ilmu-ilmu sosial secara paralel dalam rangka menghindari perilaku berisiko dan perencanaan masa depan (Kathrin F. Stanger-Hall, 2011).

Kesehatan reproduksi dan seksualitas remaja masih merupakan tantangan berat di seluruh belahan dunia. Agenda Sustainable Development Goals merefleksikan pentingnya citizenship kaum muda, otonomi, hak, dan hubungan aktif dan sehat di masyarakat sebagai aspek inti perkembangan kaum muda. Kurikulum pendidikan seks komprehensif (comprehensive sexual education-CSE) diterapkan di beberapa negara dan bervariasi di antara sekolah, dan di Amerika Serikat terbukti lebih efektif dibanding abstinence-only programs. Terdapat hubungan signifikan antara eksposur masing-masing komponen CSE dan dampak kesehatan terkait (Castro, Rojas-martı, \& Uribe-zu, 2018). Pendikan seksualitas komprehensif terdiri dari beberapa komponen yang ketika diterapkan berdampak pada pengetahuan, sikap, dan perilaku remaja. Desain komponen dan materi spesifik disesuaikan dengan situasi (termasuk permasalahan, budaya dsb.) diperlukan untuk mengupayakan keberhasilan agenda SDG bagi aspek perkembangan remaja Indonesia.

Meskipun abstinensi merupakan metode paling efektif mencegah kehamilan dan Infeksi Menular Seksual (IMS), tidak semua remaja memilih berperilaku abstinensi. Biaya yang dikeluarkan untuk program hanya abstinensi demikian besar dan intervensi komprehensif berbasis sekolah belum menjadi norma di AS (Dawson, 2018). Salah satu penelitian menemukan kesulitan bagi guru dan orang tua untuk menyampaikan informasi kesehatan reproduksi dan seksualitas. Dibutuhkan tenaga kesehatan dan psikolog untuk menyediakan informasi dan layanan tersebut di sekolah (Tabong et al., 2018).

Kewajiban memberikan pendidikan seks bukan hanya menjadi tanggung jawab orang tua dan guru, namu juga bergeser ke petugas kesehatan di layanan primer (puskesmas), terlebih dengan banyaknya kasus seksualitas dan reproduksi yang terjadi pada anak. Masih banyak orang tua di Indonesia yang menganggap diskusi tentang seksualitas sebagai hal tabu untuk dibicarakan dengan anak. Data SKRRI 2017 memperlihatkan hanya kurang dari $50 \%$ remaja 
membicarakan permasalahan seks Banyak kasus perilaku seks dan kekerasan (menstruasi dan mimpi basah) kepada orang tua mereka. Demikian juga dengan guru, angkanya berada pada kisaran 15$20 \%$, padahal akses terhadap internet dalam 1 bulan terakhir hampir mencapai 90\%. Diperlukan kerja sama berbagai pihak dengan program yang terintegrasi dan berkelanjutan untuk memastikan semua informasi (dan layanan) yang dibutuhkan remaja dapat diakses.

Situasi yang terjadi di Indonesia, berdasarkan analisis keberlangsungan (survival analysis) menunjukkan bahwa remaja yang tidak menerima atau hanya menerima salah satu dari materi pendidikan kesehatan reproduksi memiliki hazard ratio yang lebih besar (berturutturut 1,$55 ; 0,99$ dan 2,26. Remaja yang menerima informasi secara lengkap (tentang pendidikan seks) memilih perilaku abstinensi lebih lama. Remaja yang melakukan penyalahgunaan obat, merokok, minum alkohol, laki-laki, berusia 20-24 tahun dan miskin berpeluang lebih besar untuk melakukan hubungan seksual pranikah (Pinandari et al., 2015).

Secara teoritis perkembangan kognitif dan psikososial baru mulai terjadi pada usia 12 tahun (Brown, 2016) namun secara fisik sudah terjadi percepatan pertumbuhan tubuh sejak usia 10 tahun.

atau penyimpangan seks juga terjadi di usia anak masih duduk di sekolah dasar bahkan di taman kanak-kanak. Remaja Indonesia memerlukan pendidikan seks dengan berbagai topik spesifik secara komprehensif dan dilakukan sejak usia dini sesuai perkembangan kognitif dan psikososialnya.

Program edukasi harus dilakukan sejak dini karena seiring pertambahan usia efektifitasnya akan berkurang (Smith et al., 2017). Perlu diperhatikan juga usia menarche dan mimpi basah pertama kali sebagai tanda primer pubertas yang saat ini terjadi pada usia semakin muda. Namun demikian, masih ada sisi positif yang potensial untuk diperkuat. Pernikahan masih diyakini sebagai lembaga yang melegalkan hubungan seksual oleh sebagian remaja (Menon, Kusanthan, Mwaba, \& Juanola, 2018). Salah satu aspek yang perlu diperhatikan yaitu agama. Pelajar dengan tingkat religi intrinsik tinggi lebih menerima konsep abstinensi. Sebaliknya, mereka dengan religius ekstrinsik tinggi lebih menolak konsep (Ashley, Ramirez, \& Cort, 2013). Keyakinan keagamaan menjadi variabel internal bagi penerimaan konsep abstinensi, sedangkan sebaya, struktur keluarga, dan pendidikan orang tua mempengaruhinya dari luar. 


\section{KESIMPULAN}

Sebanyak $65 \%$ responden melakukan abstinensi dan 81,6\% merasa membutuhkan pendidikan seks. Hampir separuh $(47,8 \%)$ responden menginginkan metode pendidikan secara tatap muka. Pentingnya edukasi terkait hal ini merupakan salah satu upaya antisipasi bonus demografi agar tidak menjadi beban atau bahkan bencana demografi serta pencapaian SDG tujuan 3 dan 4. Situasi banyaknya proporsi penduduk produktif yang tidak dibarengi dengan peningkatan kualitas akan mengakibatkan permasalahan lain yang lebih kompleks. Diperlukan penelitian lanjutan tentang perilaku abstinen remaja Indonesia yang lebih komprehensif serta kajian tentang intervensi edukasi yang sesuai dengan sosio-kultur masyarakat.

\section{UCAPAN TERIMA KASIH}

Ucapan penghargaan dan terima kasih terutama ditujukan kepada mahasiswa Fakultas Kesehatan Masyarakat Universitas Muhammadiyah Jakarta, khususnya kelas kesehatan reproduksi dan kelas komunikasi kesehatan semester gasal 2018/2019 yang sangat membantu proses pengumpulan data. Terima kasih secara khusus kepada
Sita Retno Indriyani dan Leandra Binar Ilyasa sebagai koordinator mahasiswa.

\section{DAFTAR PUSTAKA}

Ali, Mohamed M. and Cleland, J. (2018). Long term trends in behaviour to protect against adverse reproductive and sexual health outcomes among young single African women. Biomed Central Reproductive Health, 15:136, 1-11.

Ashley, G., Ramirez, O., \& Cort, M. (2013). Attitudes toward sexual abstinence among Black SeventhDay Adventist college students. Christian Higher Education, 12(5), 349-362. https://doi.org/10.1080/15363759.20 13.824353

Biccard, B. M. (2018). Addressing the unfinished agenda on sexual and reproductive health and rights in the SDG era, 6736(18), 2581-2584. https://doi.org/10.1016/S01406736(18)30890-0

BPS. (2017). WELFARE STATISTICS 2017. Badan Pusat Statistik/BPSStatistics Indonesia (Vol. 1). https://doi.org/10.1111/j.14697610.2010.02280.x

Brown, J. E. (2016). Nutrition Through the Life Cycle. Journal of Nutrition Education and Behavior (Vol. 48). https://doi.org/10.1016/j.jneb.2015.0 8.002

Castro, F. De, Rojas-mart1, R., \& Uribezu, P. (2018). Sexual and reproductive health outcomes are positively associated with comprehensive sexual education exposure in Mexican high- school students, 1-16. 
https://doi.org/10.1371/journal.pone. 0193780

Center for Population Research and Development, B.-N. P. and, \& Family Planning Board, I. (2018). Indonesia Demographic and Health Survey 2017: Adolescent Reproductive Health Key Indicators Report.

Dawson, R. S. (2018). Adolescent Sexual Health and Education: Where Does the Pediatrician' $\mathrm{s}$ Responsibility Fall ? PEDIATRIC ANNALS, 47 no 4. https://doi.org/10.3928/1938235920180321-01

Kabiru, C. W., \& Ezeh, A. (2007). Factors Associated with Sexual Abstinence among Adolescents in Four SubSaharan African Countries. African Journal of Reproductive Health, 11(3), 111. https://doi.org/10.2307/25549735

Kathrin F. Stanger-Hall, D. W. H. (2011). Abstinence-Only Education and Teen Pregnancy Rates: Why We Need Comprehensive Sex Education in the U.S. PLoS ONE, 6 (10)(october 14, 2011), 201-208.

https://doi.org/10.1371/journal.pone. 0024658

Menon, J. A., Kusanthan, T., Mwaba, S., \& Juanola, K. (2018). ' Ring' your future, without changing diaper Can preventing teenage pregnancy address child marriage in Zambia? Public Library of Science, (October 22, 2018), 1-18.

https://doi.org/10.1371/journal.pone. 0205523

Ott, M. A., Pfeiffer, E. J., \& Fortenberry, J. D. (2006). Perceptions of Sexual Abstinence among High-Risk Early and Middle Adolescents. Journal of
Adolescent Health, 39(2), 192-198. https://doi.org/10.1016/j.jadohealth.2 005.12.009

Pinandari, A. W., Wilopo, S. A., \& Ismail, D. (2015). Pendidikan Kesehatan Reproduksi Formal dan Hubungan Seksual Pranikah Remaja Indonesia. Kesmas: National Public Health Journal, 10(1), 44. https://doi.org/10.21109/kesmas.v10i 1.817

Rasberry, C. N., \& Goodson, P. (2009).

Predictors of secondary abstinence in U.S. college undergraduates.

Archives of Sexual Behavior, 38(1), 74-86.

https://doi.org/10.1007/s10508-0079214-z

Shiffman, J., Kunnuji, M., Shawar, Y. R., \& Robinson, R. S. (2018).

International norms and the politics of sexuality education in Nigeria.

Globalization and Health, 14(1), 114. https://doi.org/10.1186/s12992018-0377-2

Smith, T. E., Panisch, L. S., Malespin, T., \& Graça Pereira, M. (2017). Evaluating effectiveness of abstinence education. Journal of Evidence-Informed Social Work, 14(5), 360-367. https://doi.org/10.1080/23761407.20 17.1340860

Tabong, P. T., Maya, E. T., Adda-balinia, T., Kusi-appouh, D., Birungi, H., Tabsoba, P., \& Adongo, P. B. (2018). Acceptability and stakeholders perspectives on feasibility of using trained psychologists and health workers to deliver school-based sexual and reproductive health services to adolescents in urban Accra, Ghana, 1-17. 
